\title{
Truth or Dare? - How can we Influence the Adoption of Artificial Intelligence in Municipalities?
}

\author{
Cindy Schaefer \\ University of Siegen \\ Cindy.Schaefer@Uni-Siegen.de \\ Maija Ylinen \\ Tampere University \\ Maija.Ylinen@tun.fi
}

\author{
Kristina Lemmer \\ University of Siegen \\ Kristina.Lemmer@Uni-Siegen.de \\ Patrick Mikalef \\ SINTEF Norway \\ Patrick.mikalef@sintef.no
}

\author{
Kret Samy Kret \\ University of Siegen \\ Kret.Samykret@Student.Uni-Siegen.de \\ Bjoern Niehaves \\ University of Siegen \\ Bjoern.Niehaves@Uni-Siegen.de
}

\begin{abstract}
Artificial intelligence (AI) is becoming an increasingly important factor of everyday life. The progress of AI adoption continues to accelerate with increasing investments in AI techniques and applications worldwide. However, the use of AI is still not present in employee's daily life of German municipalities. Since this technology has a promising potential that German municipalities can also take advantage of, it is important to facilitate the transition of municipalities to AI. For this reason, we have conducted semi-structured expert interviews in twelve German municipalities to examine perceived challenges of AI adoption from employee's perspective. Using methods from Grounded Theory and Gioia we extended research regarding the Technology-Organization-Environment (TOE) framework. Our results proof six and identified four additional perceived challenges of AI adoption in municipalities. With these results, we are able to extend literature on the use of $\mathrm{AI}$ in the public sector introducing perceived challenges of AI adoption from employee's perspective in municipalities extending the TOE Framework.
\end{abstract}

\section{Introduction}

Artificial intelligence (AI) is a young technology at the beginning of its development, but already of increasing attention [8]. In an AI study by Accenture, $86 \%$ of 300 public sector leaders want to "increase or significantly increase" spending on AI for 2020 [1]. $90 \%$ of the participants in the study expect medium to high return on their investment. Therefore, AI has the potential to double annual economic growth rates by $2035[1,8]$.

The first discussion on computer-based $\mathrm{AI}$ is often attributed in the literature to the mathematician Alan Turing, who is regarded as fundamental to computer science, among others [8]. He described in 1950 "The
Imitation Game", commonly known as the Turing Test, which is intended to test the communication capability of a machine [8]. Shortly thereafter, at a conference in Dartmouth in 1956, Stanford professor and founder of the field of AI John McCarthy gave a first characteristic term for AI $[3,15,28]$. Today we have reached a point, where the innovation of AI, among other digital trends, is increasing exponential $[10,37]$. An example for the progress of $\mathrm{AI}$ is the victory of an AI system over the world champion Lee Sedol in the GO board game in 2016. The Alpha GO AI system from Google's DeepMind, had previously learned by playing the game "against itself repeatedly, learning from its mistakes and developing novel strategies" and therefore needed no more human instructions [19].

However, the use of AI is not limited to complex board games anymore. Private companies are starting more and more to exploit the advantages and applications of AI. For example, organizations like Google and Microsoft, among others, have bought up more than 140 AI companies since 2011 [28]. The interest of private companies is growing, as is the investment in AI technologies, especially in machine learning techniques, whose progress has contributed to the wide application and usage of AI $[8,11]$.

Furthermore, these private companies support a diversified use of AI applications in everyday life, society, and to the change of the processes in the industrial sector. In everyday life, the average person uses AI more often than one might think. From intelligent search engines and navigation systems from Google to digital assistants like Amazon's Alexa or social media services from Facebook. Social applications of AI include the use of intelligent security systems and surveillance services of public institutions, or medical diagnostics provided by AI based software. Within companies, $\mathrm{AI}$ is used in processes ranging from predictive maintenance and supporting intelligent robots in the industry, to the application process of new 
employees solved by AI and the distribution of smart, AI-related products by the manufacturers [25, 30] influencing technological, organizational, and environmental outcomes.

Despite these advances in the private sector and the applications created and used by the general public, the public sector itself has only recently begun to implement AI [34]. In order to understand this discrepancy in usage, we analyzed existing literature on the public sector and administration that are using AI. In the process of our study, we realized that the majority of research articles found, dealt with either challenges, opportunities, impact, or potential of AI in the public sector from organizational point of view [34]. For example, we found a Norwegian study on opportunities and challenges for Norwegian municipalities, which aimed to investigate to which extent municipalities have implemented AI and are using the potentials of this technology [26]. However, research lacks a similar study on German municipalities. Previous studies should be adapted to German municipalities, because they differ from other European countries due to their hierarchical structures in the system (e.g., district vs. regional municipalities) and the governmental pressure they are exposed to (e.g., eGovernment development, general attitude towards technology or digital services adoption), which may limit the adoption and use of AI. As research regarding AI adoption from an employee's perspective, especially in Germany, is still sparse, we seek to fill this gap by identifying perceived challenges for adoption of AI from employee's perspective.

Conducting ten interviews with Chief Digital Officers (CDO) in German municipalities provided insights into the reasons why there is still a lack of successful use of AI in German municipalities. For future research, we will conduct a quantitative research study based on this study, in which also civil servants without IT background such as managers, end users or politicians will be interviewed about the use of AI in public administration services.

This paper is structured as follows: Firstly, we describe the background of this study demonstrating the need to identify perceived challenges for the adoption of AI in the public sector. In section 3, we describe our methodology. In section 4, we show the findings of our study and in section 5, we provide our model of perceived challenges for the adoption of $\mathrm{AI}$ in municipalities. We conclude by discussing our findings and our model and by showing limitations of our study, proposing ideas for future research.

\section{Theoretical Background}

AI is becoming more and more important in theory and practice and promises to change the world within the next decade [4]. Yet, AI is not an exactly defined term [15], but rather a collective term for various applications and technologies [21]. However, AI, as described in theory, has existed since the 1950s but changed over time [3]. It was first introduced at a conference in Dartmouth in 1956 with the words of McCarthy as the "science and engineering of making intelligent machines, especially intelligent computer programs" [3]. In addition, Valle-Cruz et al. defines AI as computational intelligence, meaning that intelligent machines have "the capacity to learn, rationalize, and process certain instructions to be followed or to perform an action" [37]. Aligning to previous research and the development of the term of AI during the past 70 years, we use the following definition of AI "AI refers to systems that are able to correctly interpret external data, to learn from such data, and to use those learnings to achieve specific goals and tasks through flexible adaptation", aligned to Kaplan (2019) [22].

However, with new technologies arising, one has to adapt their behavior to new possibilities of usage. Sometimes this causes perceived challenges for IT adoption from a user's perspective. The adoption of technology is described as the "choice to acquire and use a new invention or innovation" and diffusion as "the process by which something new spreads throughout a population" [17]. Taking the fact into account that organizational, cultural, and legal issues need time to change, this process of diffusion and adoption can take years. In theory, there are already many models for the adoption of IT innovations. Models used for organizational level analysis are e.g. the Diffusion of Innovation Theory [31] and the TechnologyOrganization-Environment (TOE) framework [18].

The adoption of technology is multidimensional, with many factors that need consideration. As an example, the TOE framework can be used as a commonly used theoretical framework to examine different aspects of IT deployment in organizations [29]. In addition, research on the adoption of innovative technologies (e.g. Big Data) in organizations with the TOE framework has already proven useful [2], for example in similar digital trends such as cloud computing and business intelligence systems [29, 40].

In the TOE framework the technological, organizational, and environmental dimensions are considered [18, 31]. The technological context describes all relevant technologies to an organization, which are available outside as well as inside a company. According to this, even innovations and technologies, which are not used internally are influential in the technological dimension, as they can reveal new possibilities for an organization. The organizational context refers to the characteristics and resources of the institution, such as internal structures and processes, 
size of the organization, and unused, free resources. The environmental context includes external influences from the environment, e.g. pressure or competition from industry or regulatory frameworks. [29]

In conclusion, existing empirical research on AI adoption in the public sector is still sparse. Present studies on AI adoption have so far only been focused on the organizational level in the private sector. But since more and more public managers are becoming inclined to use AI applications in the public sector the need for studies on AI adoption in the public sector from an employee's perspective increases [25, 26, 34]. Focusing on the private sector, a study regarding factors which influence the adoption of AI from an employee's perspective in organizations [4] and a study investigating organizational AI-readiness [2] as well as organizational readiness factors related to AI exist in recent literature [29]. However, emphasizing the difference between the private and public sector (e.g. motivation of employees, non-profit-making intent, different work time models, more intrinsic motivation goals, and the diverse spectrum of values) we recognize a need for studies analyzing perceived challenges for adoption of AI in municipalities from the employees perspective [25, 26, 29]. Based on this, we finally derive our research question (RQ).

RQ: Which perceived challenges face employees regarding the adoption of $\mathrm{AI}$ in German municipalities?

\section{Method}

Method Selection. In our study we used an explorative approach to gain suitable insights into perceived challenges for adoption of AI in public administrations of municipalities from employees perspective $[12,29]$. Since qualitative research offers more opportunities to observe the phenomena under study more closely, and since more recent research calls for the use of more qualitative and mixed methodological approaches to study the perceived challenges to the adoption of AI by community employees, this research takes an explorative qualitative approach. To support our explorative approach, we have decided to use tools from Grounded Theory [13, 14].

Data Collection. Within ten digital interviews (about 45 minutes in average) we have surveyed eleven municipalities in Germany as well as the district administration of these municipalities itself. There were ten interviews, since one interviewer represented three municipalities. The district administration describes the next higher level of municipalities in which smaller municipalities are organized in Germany. For example, one task of the district administration is to support its municipalities regarding the infrastructure of hospitals and Smart Mobility. The district is also managing combined digital transformation projects of municipalities, regarding the use of joint systems. The interviewed municipalities together with their district are involved in a regional digital transformation strategy and work with the same external (and regional) service provider. Both the size and the number of inhabitants differ within these municipalities (see Table 1).

The interviewees have different professions and hierarchies within their municipalities. This distribution across hierarchical levels was coincidental, but together with the different number of years in profession and professional experience, it can be ensure that personal and "elite" bias are avoided and different perspectives are considered [27, 29]. These eleven interviewees represent their municipalities and are the respective digitization experts of these municipalities and thus key informants [29, 33].

Table 1: Interview information

\begin{tabular}{|c|c|}
\hline Job titles & $\begin{array}{l}\text { CDO, IT administrator or project } \\
\text { manager (specialized on digitization } \\
\text { topics) }\end{array}$ \\
\hline $\begin{array}{l}\text { Hierarchy } \\
\text { levels }\end{array}$ & $\begin{array}{l}\text { IT management, human resources \& } \\
\text { organizational management, CDO }\end{array}$ \\
\hline $\begin{array}{l}\text { Population } \\
\text { by } \\
\text { categories }\end{array}$ & $\begin{array}{ll}0-15.000: & 5 \text { municipalities } \\
15.001-30.000: & 4 \text { municipalities } \\
30.001-45.000: & 1 \text { municipality } \\
>100.000: & 1 \text { city } \\
>250.000: & 1 \text { district }\end{array}$ \\
\hline $\begin{array}{l}\text { Interview } \\
\text { structure }\end{array}$ & $\begin{array}{l}\text { 1. Interviewee introduction; } 2 \text {. AI in } \\
\text { general; } 3 \text {. Implementation; } 4 \text {. } \\
\text { Challenges; } 5 \text {. Potential; 6. Strategy; } \\
\text { 7. AI \& Citizen }\end{array}$ \\
\hline
\end{tabular}

For the interviews we used a semi-structured guideline with open questions to allow the participants to speak freely and to get a wider range of answers [29]. Due to the rare use of AI in the municipalities, the interviewees required time to prepare the interview topic, so the questionnaire was sent to the interviewees in advance and the interview was conducted with it. Thus, we followed the guiding principles for a qualitative research according to Sarker et al. [33] and avoided pitfalls of semi-structured qualitative interviews [29, 33]. With twelve interviewed municipalities or district we are on a par with other qualitative researches that have dealt with the topic of adoption of similar technologies [29].

During the interviews we made notes on what could be improved in the questionnaire and the way of interviewing in order to get optimal results and information from further interviews. After the first interview, the questionnaire was slightly optimized by adding a few more questions.

The questionnaire is divided into seven categories. We started with the introduction of the interviewee and general questions about the definition of AI. Afterwards 
we asked questions related to a possible AI implementation process in municipalities, for example: "What are the requirements to implement AI?". Furthermore, we identified potentials and threats with questions such as "Where do you see threats and potentials for AI in your municipality?". Finally, we went into asking strategic questions proposing potential use of AI, such as "What are action recommendations to deal with challenges and exploit potentials of AI in municipalities?". We concluded the interview with an outlook which included the citizen perspective and the impact AI usage in the municipality has on them.

Data Analysis. The recorded interviews were transcribed with the software f4transkript and the transcripts then were analyzed with MAXQDA. In order to analyze the interviews we used coding methods (e.g. open coding, axial coding and selective coding) from Grounded Theory and started to analyze the data using open coding $[9,13,14]$, meaning that we searched for perceived challenges of AI adoption line by line. In this phase we aligned to Gioia and proposed $1^{\text {st }}$-order concepts reflecting the perceived challenges. Within our team we have carried out this process of open coding independently from each other to achieve a wide range of results. After this step, related codes and $1^{\text {st }}$-order concepts were categorized and grouped as a $2^{\text {nd }}$-order themes (axial coding) to harmonize themes helping us to specify and label perceived challenges [9, 13]. This method can be illustrated by the following statement of an interviewee:

"We have a very ambitious IT specialist for three or four years now, who I think has already made a lot of progress here. In terms of the personnel resources with regard to the strategy in a competence team, I honestly don't really see the use of AI yet, because, in my opinion, we are all so busy with our work that there are no human resources to deal with AI." -M9

Two independent $1^{\text {st }}$-order concepts ("Recruiting AI specialists for competence teams" and "Employee training and knowledge transfer") were identified. Based on these concepts, the $2^{\text {nd }}$-order theme ("competencies \& capacities") was identified as theme and terminology. In a last step, we concluded our analysis by linking our results to existing literature further elaborating our $2^{\text {nd }}$-order themes into theoretical "aggregate dimensions" (selective coding, Grounded Theory approach) $[9,13]$. In our example, the aggregate dimension was called "perceived technical competences" (see Figure 1). Interpretational differences along the researchers were discussed intensively to find a solution that is in the interest of all researchers. We finished our analysis when the point of saturation was achieved, e.g., when no further aggregate dimensions emerged.

\section{Findings}

Perceived direct benefits. In the interviews, we have repeatedly noticed that perceived direct benefits of the AI technology are conducive to the promotion of AI adoption in municipalities. The potential of AI is increasingly perceived as the automatization of processes and as an assistance system for the administration. Economic advantages can be generated through savings, and new and more creative solutions.

Self-learning assistance systems, which are constantly evolving and optimizing themselves and which streamline and automate processes, can relieve employees. The assistance systems can better structure and prepare the data volumes that will be generated in the future and thus relieve the administrative employee. In this way, the focus of the employees can be shifted to the core processes of the administration and the administrative staff can spend more time to better respond to the individual needs of their citizen. One such assistance system could, for example, be a chatbot that accepts citizens' queries and thus offers advantages such as 24-hour service and faster, consistent processing quality. One of our interviewed municipalities explains the function of such a system:

"Further I see there is also the aspect of the assistance systems. In other words, that these are systems that solve problems efficiently on their own and learn from error situations [...]." -M6

The savings potential is economically in cost savings (personnel costs, resources). For example, over time, an AI system can be more cost effective compared to an employee leading to resource savings through process automation. Illustrated by one municipality:

"If you talk about automation and processes [...] and then maybe go one step further, I think you naturally come to saving resources" $-M 3$

The independent AI systems can also generate new, creative, and cross-dimensional solution approaches, that, for example consider and further develop aspects of sustainability. Emerging and already highly developed AI techniques such as translation services, image, face, text, speech, and pattern recognition could be a solution to a smart administration. These techniques would allow the stronger connection and involvement of the citizens in the activities of the municipality and the inclusion of people with disabilities in their daily life. The latter is explained in more detail in the following:

"I do believe that digital transformation as a whole and through AI will have a great impact. [...] So, when I think of people with disabilities, for example with speech recognition and systems that react (correctly) to voice input, it can certainly achieve improvement [...]." $-M 1$ 
The dimension of "perceived direct benefits" can be found in the existing literature by Kuan \& Chau [23]. For example, in their study on the adoption of electronic data interchange (EDI) in small businesses, they presented a perception-based model in which perceived direct benefits play an important role in the TOE frameworks they apply. In our study we define perceived benefits [23] as the benefits that are perceived rather than the benefits that are actually delivered or enabled by technology. The term "direct" relies to operational advantages. Therefore, perceived direct benefits lead to an increase in performance of daily internal processes of an organization. "Relative advantage" [23], which was used by Rogers [31] (adoption of innovations) and by Iacavou et al. [20] (adoption of technology), is described as an important factor for technology adoption [23].

Perceived indirect benefits. The interviews revealed that project orientated measures as well as communication and cooperation with other municipalities result in strategic and indirect benefits and lead to a promotion of adoption of $\mathrm{AI}$ in municipalities.

Project orientation means the participation on overarching projects, which are operated by an external service provider. In addition, the municipalities should start with best practices and small pilot projects of AI, because their impact is known and these projects have been successfully implemented before. Furthermore, digital transformation projects should generally be more encouraged, as these will ultimately contribute to the promotion of AI in municipalities. One example of a municipality shows such a commitment to an overarching project:

"Then there is the regional project of autonomous driving in the field of mobility, where we are virtually involved, e.g., autonomous driving." -M3

Another municipality has a similar approach:

"Maybe you should start small with pilot projects [...] to see what the reactions are like, how is the user behavior [...], and what kind of feedback is there. " -M4

To further promote the use of AI in one's own municipality, communication is a beneficial factor. There should be a strong exchange with other municipalities and existing institutions regarding regional joint projects and potentials of AI. In this context, cooperation should be initiated with other municipalities to utilize shared potentials (e.g., in the tourism sector). Communication and cooperation ensure that the topic of AI is addressed and increases the chances of implementing this technology at a later point in time. A joint project collaboration between the municipalities that exists in the field of tourism looks like this:

\section{"There is a [...] Project [and] the topic [is] the}

evaluation of visitor flows [...] especially tourism [...]. We will use AI technologies for person recognition and maybe face recognition [...]. This is an association of five municipalities here in our region." -MI

In the literature [23] referred to as "perceived indirect benefits" in their perception-based model. The terminology "perceived benefits" are the "perceived benefits rather than benefits that are actually provided" $[20,23]$ by the technology. The term "indirect" derives from the fact that the benefits are strategic, e.g., they are caused by external relationships with business partners or competitors.

Compatibility. In our interviews the municipalities stated that the technical compatibility of their IT systems with the new AI technology is of great importance and has a decisive influence. A technological foundation, namely a modern IT infrastructure, is a prerequisite for AI technology and digitization itself. Therefore, the existing processes in the administration have to be digital transformed and reengineered as well as outdated systems have to be prepared for the new AI systems. The old technical systems of the municipality have to change to a modern, multi-dimensional compatible software. In order to achieve this, the municipality can cooperate with other municipalities as above mentioned or with the involvement of a third-party provider. For example, one municipality sees its IT infrastructure as a major problem to AI adoption:

"This is simply because we are still sick of the fact that we are still using outdated IT systems. That we are also still using old software, which cannot provide any interfaces [to AI]". - M10

The term compatibility in connection with the adoption of technologies is frequently used in the literature and describes "the degree to which an innovation matches the actual needs of the potential user organization" $[18,29]$. Many studies referred to it as e.g. diffusion of innovation [31], adoption of customerbased interorganizational systems [16], or exploring organizational readiness factors for AI [29]. So this is the first aggregated dimension added to the TOE framework, according to Salleh and Janczewski [32].

Perceived technical competences. The interviews repeatedly pointed out the importance of human resources in relation to technical competences. Technical competencies and the staff capacity within the administration are perceived as necessary and conducive for the implementation of AI projects.

Know-how is a basic precondition for leveraging the potential of AI. It is therefore beneficial to educate employees through knowledge transfers or training courses. Apart from trained staff the employment of AIspecialists could lead to proper and beneficial AI applications and solutions development for the 
respective municipality. In competence teams' holistic concepts could be elaborated and executed in an expert office. Further, human capacities are needed to deal with the subject of AI alongside with the daily administrative work of the municipality. One municipality reflects this:

"First of all, know-how must be built up here. Without know-how I cannot successfully implement anything myself." -M1

The perception-based model [23] directly refers to the "perceived technical competences". In their studies they use this dimension because organizational resources and therefore technological competences are crucial to enable the implementation of the advantages a technology offers. Since [23] the use of a perceptionbased model, also distinguishes in this context that the perceived competencies are of importance. In their literature review on IT adoption, Zhu and Kraemer [40] also found that "technological competence" has been used extensively in previous studies.

Perceived financial cost. Further, the financial aspects of the adoption of AI must be considered. Therefore, the perceived financial costs are an influencing factor.

The CDO's pointed out that the promotion of AI deployment is particularly dependent on the financial resources required for implementation and utilization. The costs must therefore be taken into account. But besides the costs which arise for the implementation, AI also offers the potential of financial advantage over time because AI can excel in efficiency and automation compared to personal resources, especially in routine processes. This is expressed in the following:

"Once implemented the AI certainly does not cost as much money as the daily employee. [...] On the economic side, there is a high savings potential." -M10

The perceived financial costs are reflected in the perception-based model of [23] as well. Taking an employee's perspective shows that since costs can be perceived differently, we used the termination of perceived costs. This is due to the fact that what is perceived as high financial costs for one person may be low for another [20, 23]. Furthermore [40] refer to financial resources in their studies meaning the financial commitment of an organization.

Strategic alignment. Another aggregated dimension identified in the interviews is strategic alignment according to Avision et al. [5] Thoughtful planning of AI adoption creates an increased likelihood of enabling this strategy and therefore the AI technology. In this strategic process, the creation of transparency about the AI processes must be considered as well as the formation of acceptance for AI. Additionally, the municipality should be orientated on existing strategic documents in the process of the strategic planning. Transparency in this context refers to the fact that methods, as well as a framework is provided beforehand by the municipalities to guarantee the explainability and control of self-learning systems over time, leading to the promotion of AI adoption. One explanation of this is provided by:

"The algorithms change by themselves so much that the original developers who created them no longer understand them themselves. I think that you also have to develop methods, technical methods, that create this transparency." -MI

Another point is the importance of transparency within the process of strategic alignment as well as the need of a shared common understanding and definition of AI inside a municipality is highlighted by M3:

"Then transparency is also a success factor that you have to create in the process. What goals do we want to achieve and how do we want to achieve them and what is AI and what can it achieve by itself [...]." -M3

In addition to transparency there also needs to be acceptance for AI solutions and applications. Acceptance can be created by identifying stakeholder at an early stage of the project planning who take responsibility and commitment for the transition to AI applications. As the service is ultimately intended for citizens, they should not be neglected in this process and therefore opportunities for citizen participation should be offered in the project planning to improve acceptance. Moreover, the sovereignty of humans over the AI systems as well as a low error rate of the systems and their reliability should always be assured. E.g., M4 explains in the following quotation the necessity of creating acceptance:

"But what I think is important in order to make any progress at all in this topic is to create acceptance: On the one hand, on the administrative side [...]. And on the other hand, of course, on the side of the citizens, the customers [...]." -M4

Another point that leads to the facilitation of AI in the municipalities is the existence of strategic documents. These documents can be a status-quo report on the current use and identified added value of AI for the municipality or the inclusion of recommendations for action that consider how municipalities should deal with AI. The strategic alignment process can be based on higher-level strategic documents of the federal and state governments. Moreover, AI can be used as a tool to achieve objects of existing strategies. For example, the need of the existence of strategic documents is confirmed by one municipality in the following statement:

"First of all, I believe that what is missing is that there are no recommendations for action [for AI in municipalities]" - M7

There are studies in the literature that refer to strategic alignment [18]. For example, Grover [16] used 
the term strategic alignment in his study on the adoption of customer-based interorganizational system, referring to it as "the extent of strategic IS planning" and emphasizing the importance of linking the organizational strategy with the IS strategy. Thong [35], in his studies about IS implementation in small businesses, also points out the importance of planning, meaning that the higher the effort of planning, the more successful the implementation.

Organizational innovativeness. From the interviews we can derive that open-mindedness and organizational innovativeness towards AI as well as digital transformation is another key factor to adopt AI. Organizational innovativeness is characterized by the fact that employees are motivated to embrace new innovations within their organization.

The individual motivation of employees must be met and plays a role to enhance AI adoption. It is important that e.g., management and administrative staff identify themselves with the topic of AI and think flexibly and innovatively to carry out the implementation successfully. The motivation and the own will to change the image of the administration and to change old working methods should be given. The process of dealing with the topic of AI adoption should simply get started, there should not be endless discussions back and forth. The following quotation illustrates the importance of individual motivation:

"As an administrator, I must therefore commit to this topic and state: 'This is now our new technology, this is the new way in which we want to work with assistance, and we will then implement it at the workplace throughout the administration. "' -M4

Transferring organizational innovativeness back to theory shows that Lai and Guynes [24] use the term openness as an important adoption decision factor and describe it as "the degree to which an organization is willing to infuse innovation". [24] use this term in an organizational context to examine ISDN (integrated services digital network) adoption in U.S. companies.

Perceived industry pressure. The diffusion of technologies exerts pressure on municipalities that encourages the adoption of AI. For example, the decreasing costs of technology, wider availability, and mass access to innovations over time are consequences of the technology's diffusion. Due to this diffusion, more companies enter the private market. The increasing number of competitors on the market leads to more improved services. These services could meet the requirements of municipalities, such as continuous support and quality of the AI systems by the manufacturers, and therefore enhance AI adoption. An example, based on the diffusion of technology, which

illustrates this view:

"What seems to be impossible for a long time is suddenly made possible by such a situation [COVID 19 crisis]. And it is the same if somewhere technology suddenly becomes cheaper, more tangible, or more feasible [...]. Then there is also change or even acceleration." -M6

The influence of the industry has also been stated by [23]. They rank the "perceived industry pressure" as an aspect of environmental pressure e.g., through business partners or competitors that leads to technology adoption. Zhu et al. [39] and Zhu \& Kraemer [40] describe this factor as "competitive pressure". In sum, this is the third added aggregated dimension according to Venkatesh and Bala [38].

Perceived government pressure. The evaluation of the interviews has shown that pressure from the government is conducive to the implementation of AI. Official guidelines must come from the government as well as the definition of a standard of legal and security matters.

It can be supportive for the implementation of $\mathrm{AI}$ if the government introduces official guidelines and recommendations for the handling of $\mathrm{AI}$ in municipalities. Politicians should position themselves clearly and set the switch to AI as a goal for municipalities and communicate this to the public. Action recommendations for municipalities are considered desirable, as they can use them as an orientation. One example underlines the importance of governmental pressure:

"[...] and the demands from politics: "you have to position yourself there". Then there is also change or even acceleration [of AI adoption]. " -M6

In addition to official guidelines, standards should be set by the government for data security and legal matters related to AI applications. This gives municipalities a legal protection when AI projects are implemented and guarantees citizens a service that is difficult to manipulate by given data security regulations. The DSGVO, the German version of the European GDPR (General Data Protection Regulation), is one way of dealing with the issue of data protection. In addition, further policies must be created for AI, which guarantee the confidential use of data by the municipalities as well as the prevention of data manipulation and security gaps for the public AI systems and their data. Through these standards, the government is putting pressure on municipalities to enable these standards and thereby enhancing AI adoption. For example, M7 appeals the aspect, that regulation leads to adoption of (AI) applications:

"Of course, I also see danger in legal matters. Of course, the legal prerequisites have to be created there as well. Similar to autonomous driving, for example, that the way is created for it. That such applications in certain areas can and may be used even now. " -M7 
The dimension of "perceived government pressure" is used by [23] also as an environmental factor that leads to adoption of technology. Regulatory measures and government policies exert pressure, which is perceived differently by organizations [23].

Perceived pressure from society. The perceived pressure from society is based in our case on the needs and moral standards of the society and their citizens.

In a digital world, citizens demand for a digital municipality with permanent accessibility and $24 \mathrm{~h}$ service rises. To meet this demand, the use of AI is crucial. User behavior and preferences of citizens are also changing, especially if one considers that future generations will be digital natives, e.g., generations that take digitalization for granted. Therefore, the perceived pressure to meet the demands of these citizens requirements is increasing and promotes the need and use of AI adoption in municipalities. A proof for this view is provided by following municipality:

"Above all in the upheaval of the generations, the younger generations of digital natives, are also demanding digital tools [...]." -M10

In addition, for the wide social application of AI, the clarification of moral questions is an important point, because ultimately the decisions of the algorithms must be met by the ethical standards of the citizens. The broad social discussion of these questions must be created in order to prepare the topic morally and develop ethical frameworks that developers can use and incorporate into the algorithms. One municipalities thoughts are quoted below:

"Ethical issues are a very important point, I think. Algorithms that perhaps at some point will actually make autonomous decisions about important things. This is always accompanied by ethical questions. We must first find answers to these questions." $-M 1$

In their study on the adoption of electronic government services, Tung and Rieck [36] used the effect of "social influence" as an important factor in adoption decisions. The term means that the public's view of a company is relevant, as it influences the decisions of the company. Since the opinions of the citizens are important to a municipality, the perceived pressure from society leads to the adoption of AI tech- nology by the citizens, if required $[23,36]$.

\section{Model development}

Based on our applied method of Grounded Theory and the Gioia methodology for the analysis of the interviews, we were able to proof and extend the use of the TOE framework, used in recent literature to analyze organizations, to transfer it to an individual level showing perceived challenges from an employee's perspective. We therefore were able to first, support dimension by Kuan \& Chau [23] introducing the viewpoint of employees and secondly extending the framework regarding further perceived challenges.

Honoring present literature regarding $\mathrm{AI}$ in the public administration $[6,7,34]$, we were able to identify four additional aggregated dimensions (Compatibility, Strategic alignment, organizational innovativeness, and Pressure from society) additional to the six dimensions introduced by Kuan and Chau [23]. Thus, we were able to develop in total ten dimensions of perceived challenges for AI adoption in municipalities from an employee's perspective. We were concentrating on the employees perspective in order to extend recent research on the benefits and challenges of $\mathrm{AI}$ in the public sector $[6,7]$. As Sun and Medaglia [34] concentrated on three different groups of stakeholder (e.g. government policymakers, hospital managers/doctors, and Information Technology (IT) firm managers, we concentrated on the employees who need to implement AI in their work routines. We integrated the aggregated dimensions into the TOE framework to cast our perceived challenges of employees into a theoretical context [29]. For this, we used the perception-based model of [23] as a foundation for our model, proofed and extended it with our findings from the interviews from an employee's perspective. The assignment of the different aggregated dimensions to the three pillars of the TOE framework is based on the explanation in the theoretical background section.

With our model we provide a framework of perceived challenges employees are facing when adopting AI in German municipalities [18]. Figure 1 shows our extended TOE framework.

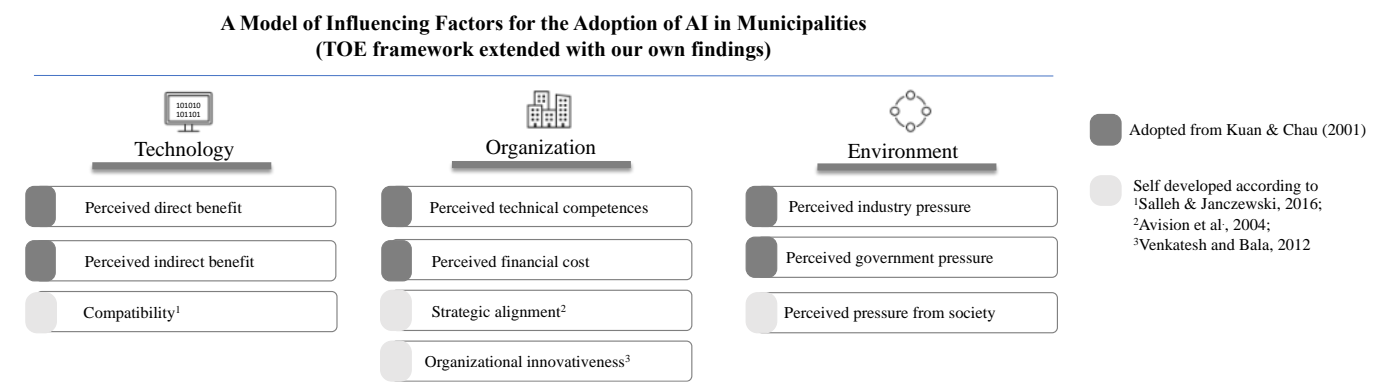

Figure 1: Extended TOE framework 


\section{Discussion}

In our interviews we interviewed eleven municipalities within a complete district as well as the district administration itself in Germany. Using coding methods from Grounded Theory applied by Gioia, we were able to proof six dimensions introduced by Kuan \& Chau [23] from an employee's perspective and identify additional four aggregated dimensions in our study. These aggregated dimensions represent perceived challenges for adoption of AI in municipalities. In a further step, we have integrated these aggregated dimensions into the theoretical context of the TOE framework, which is often used in the literature for the adoption of IT in organizations.

Our research shows implications for theory by conducting perceived challenges of $\mathrm{AI}$ adoption from employee's perspective using a qualitative explorative study. It further extends research on the adoption of AI, using classical adoption models like the TOE framework in the public sector, which differs from private sector regarding e.g., the motivation of employees. We were able to present an expanded TOE framework for AI adoption in the public sector reflecting our identified aggregated dimensions in existing literature.

As implications for practice our study enables municipalities to use our study to gain a better understanding of which challenges are important to take care of while encouraging the use of AI along employees. With these challenges we offer an orientation guide for municipalities that are switching to AI technology. We also enable managers and CDOs recommendations for actions while introducing $\mathrm{AI}$ in their municipality helping them to find motivations which support the overcoming of perceived challenges of adoption from employee's perspective.

\section{Limitations \& Future research}

In summary, we proofed six dimensions of perceived challenges from Kuan \& Chau [23] and identified additionally four perceived challenges for AI adoption extending the TOE framework for pubic administrations along an employee's perspective. We were able to add these challenges to the TOE framework proofing and showing new challenges faced by employees regarding the adoption of AI. In our study we focused on the use of AI in municipalities and took an explorative approach based on qualitative interviews. Through interviews conducted in all municipalities of one district and the district itself in Germany we were able to generate implications for research and practice.

Aligned to other empirical studies, this paper has limitations that show options for future research. Even though we aimed for qualitative rigor in our study, we still must mention typical limitations of qualitative research (e.g., weak internal validation). For example, it should be noted that we only interviewed one type of stakeholder in the process of adopting AI in municipalities. We neglected other stakeholders such as regional IT service providers or citizens and their influence, although they were considered an important factor in our findings.

Furthermore, it should be noted that we only interviewed the municipalities of one district and therefore only one area in Germany. It should be noted that the majority of the municipalities surveyed had a low population figure (below 100,000 inhabitants). Also, the respective municipalities do not have any AI applications in use yet, or just a very low number. Therefore, the time of the study (mid-2020) should be considered in this context. During this time, AI is mostly used in private companies and is just becoming more and more widespread in regional municipalities in Germany. The structure of this study is aimed at finding perceived challenges for AI adoption. No statement has been made about the importance of these challenges among each other, nor how to overcome these challenges in practice completely.

Apart from those, it is important to acknowledge the following aspects: Future research teams could examine how these challenges can be practically taken into account in the implementation process of AI application in municipalities interviewing civil servants without an IT background such as managers, end-users, or political figures. Aligned to the small number of interviewed municipalities, future research could extend our study by interviewing more municipalities adding politicians and managers to the interviewees. It would also be interesting, to repeated our study at a later point in time to examine perceived challenges when the diffusion of AI technology is more advanced. Future research could also follow an implementation process of an AI technology in the public sector to analyze challenges directly in the implementation process.

\section{References}

[1] Accenture, Transforming Public Service with AI: A GovTech Ecosystem Approach, 2019.

[2] Alsheibani, S., Y. Cheung, and C. Messom, "Artificial Intelligence Adoption: AI-readiness at Firm-Level", Artificial Intelligence 6, 2018, pp. 26-2018.

[3] Alsheibani, S.A., D. Cheung, and D. Messom, "Factors Inhibiting the Adoption of Artificial Intelligence at organizational-level: A Preliminary Investigation”, 2019.

[4] Ambati, L.S., K. Narukonda, G.R. Bojja, and D. Bishop, "Factors Influencing the Adoption of Artificial Intelligence in Organizations-From an Employee's Perspective", 2020.

[5] Avison, D., J. Jones, P. Powell, and D. Wilson, "Using and validating the strategic alignment model", The Journal of 
Strategic Information Systems 13(3), 2004, pp. 223-246. [6] Bannister, F., and R. Connolly, "The future ain't what it used to be: Forecasting the impact of ICT on the public sphere", Government Information Quarterly 37(1), 2020, pp. 101410 .

[7] Barth, T.J., and E. Arnold, "Artificial Intelligence and Administrative Discretion: Implications for Public Administration", The American Review of Public Administration 29(4), 1999, pp. 332-351.

[8] Bughin, J., E. Hazan, S. Ramaswamy, et al., Artificial Intelligence: The Next Digital Frontier?, McKinsey Global Institute, 2017.

[9] Corbin, J., and A. Strauss, Basics of qualitative research: Techniques and procedures for developing grounded theory, Sage publications, 2014.

[10] Desouza, K.C., G.S. Dawson, and D. Chenok, "Designing, developing, and deploying artificial intelligence systems: Lessons from and for the public sector", Business Horizons 63(2), 2020, pp. 205-213.

[11] Dwivedi, Y.K., L. Hughes, E. Ismagilova, et al., "Artificial Intelligence (AI): Multidisciplinary perspectives on emerging challenges, opportunities, and agenda for research, practice and policy", International Journal of Information Management, 2019, pp. 101994.

[12] Flick, U., E. Von Kardorff, and I. Steinke, "What is qualitative research? An introduction to the field", $A$ companion to qualitative research, 2004, pp. 3-11.

[13] Gioia, D.A., K.G. Corley, and A.L. Hamilton, "Seeking qualitative rigor in inductive research: Notes on the Gioia methodology", Organizational research methods 16(1), 2013, pp. $15-31$.

[14] Glaser, B.G., and A.L. Strauss, Discovery of grounded theory: Strategies for qualitative research, Routledge, 2017.

[15] Grosz, B., J., R. Altman, E. Horvitz, et al., Artificial Intelligence and life in 2030, Stanford University, 2016.

[16] Grover, V., "An empirically derived model for the adoption of customer-based interorganizational systems", Decision sciences 24(3), 1993, pp. 603-640.

[17] Hall, B.H., and B. Khan, Adoption of new technology, National bureau of economic research, 2003.

[18] Hameed, M.A., S. Counsell, and S. Swift, “A conceptual model for the process of IT innovation adoption in organizations", Journal of Engineering and Technology Management 29(3), 2012, pp. 358-390.

[19] Hassabis, D., "Artificial Intelligence: Chess match of the century", Nature 544, 2017, pp. 413-414.

[20] Iacovou, C.L., I. Benbasat, and A.S. Dexter, "Electronic data interchange and small organizations: Adoption and impact of technology", MIS quarterly, 1995, pp. 465-485.

[21] Jarrahi, M.H., "Artificial intelligence and the future of work: Human-AI symbiosis in organizational decision making”, Business Horizons 61(4), 2018, pp. 577-586.

[22] Kaplan, A., and M. Haenlein, "Siri, Siri, in my hand: Who's the fairest in the land? On the interpretations, illustrations, and implications of artificial intelligence", Business Horizons 62(1), 2019, pp. 15-25.

[23] Kuan, K.K.Y., and P.Y.K. Chau, "A perception-based model for EDI adoption in small businesses using a technology-organization-environment framework", Information \& Management 38(8), 2001, pp. 507-521.
[24] Lai, V.S., and J.L. Guynes, “A model of ISDN (integrated services digital network) adoption in US corporations", Information \& Management 26(2), 1994, pp. 75-84.

[25] Mehr, H., H. Ash, and D. Fellow, "Artificial intelligence for citizen services and government", Ash Cent. Democr. Gov. Innov. Harvard Kennedy Sch., no. August, 2017, pp. 1-12.

[26] Mikalef, P., S.O. Fjørtoft, and H.Y. Torvatn, "Artificial Intelligence in the Public Sector: A Study of Challenges and Opportunities for Norwegian Municipalities", Conference on e-Business, e-Services and e-Society, Springer (2019), 267277.

[27] Miles, M.B., and A.M. Huberman, Qualitative data analysis: An expanded sourcebook, sage, 1994.

[28] Pan, Y., "Heading toward artificial intelligence 2.0", Engineering 2(4), 2016, pp. 409-413.

[29] Pumplun, L., C. Tauchert, and M. Heidt, "A New Organizational Chassis for Artificial Intelligence-Exploring Organizational Readiness Factors", Proceedings of the Twenty-Seventh European Conference on Information Systems (ECIS2019), (2019), 1-15.

[30] Reinhart, J., and C. Greiner, "Künstliche Intelligenz eine Einführung. Grundlagen, Anwendungsbeispiele und Umsetzungsstrategien für Unternehmen", 2019.

[31] Rogers, E.M., "Diffusion of innovations", New York Free Press(4th Edition), 1995.

[32] Salleh, K.A., and L. Janczewski, “Adoption of Big Data Solutions: A study on its security determinants using Sec-TOE Framework", CONF-IRM, (2016).

[33] Sarker, S., X. Xiao, and T. Beaulieu, "Guest editorial: qualitative studies in information systems: a critical review and some guiding principles", MIS quarterly 37(4), 2013, pp. iii-xviii.

[34] Sun, T.Q., and R. Medaglia, "Mapping the challenges of Artificial Intelligence in the public sector: Evidence from public healthcare", Government Information Quarterly 36(2), 2019, pp. 368-383.

[35] Thong, J.Y., "Resource constraints and information systems implementation in Singaporean small businesses", Omega 29(2), 2001, pp. 143-156.

[36] Tung, L.L., and O. Rieck, "Adoption of electronic government services among business organizations in Singapore", The Journal of Strategic Information Systems 14(4), 2005, pp. 417-440.

[37] Valle-Cruz, D., E. Alejandro Ruvalcaba-Gomez, R. Sandoval-Almazan, and J. Ignacio Criado, "A review of artificial intelligence in government and its potential from a public policy perspective", Proceedings of the 20th Annual International Conference on Digital Government Research, (2019), 91-99.

[38] Venkatesh, V., and H. Bala, "Adoption and Impacts of Interorganizational Business Process Standards: Role of Partnering Synergy”, Information Systems Research 23(4), 2012, pp. 1131-1157.

[39] Zhu, K., K. Kraemer, and S. Xu, "Electronic business adoption by European firms: a cross-country assessment of the facilitators and inhibitors", European journal of information systems 12(4), 2003, pp. 251-268.

[40] Zhu, K., and K.L. Kraemer, "Post-Adoption Variations in Usage and Value of E-Business by Organizations: CrossCountry Evidence from the Retail Industry", Information Systems Research 16(1), 2005, pp. 61-84. 